\title{
The THOR Effect: Thyroid Hormone Offsets Retinopathy
}

\author{
Sankarnarayanan Sailesh*, Harpal S Randeva, Chris J0 Callaghan, Paul OHare, Paul 0 Hare, Sam Philip, \\ Ponnusamy Saravanan and Vinod Patel
}

Warwick Medical School, UK

Submission: July 21, 2017; Published: February 20, 2018

*Corresponding author: Sankaranarayanan Sailesh, MBBS, MD, FRCP, University Hospital Coventry \& Warwickshire NHS Trust, Clifford Bridge Road, Coventry CV22DX, UK, Tel: +44-2476-965972; Fax: +44-2476-965964; Email: sailesh.sankar@uhcw.nhs.uk

Abstract

Objective: Thyroid status has been implicated in macrovascular disease both in patients with and without diabetes, however its effect on microvascular complications has not been explored. We assessed the prevalence and time to development of diabetic retinopathy in patients with type 2 diabetes with and without thyroxine treatment.

Research design and methods: The prevalence of retinopathy was determined, in a retrospective cohort study from a secondary care referral diabetes clinic patients with type 2 diabetes and coexisting treated hypothyroidism (THD; $n=147$ ) and duration matched controls without hypothyroidism (DM2; n=383). Using Kaplan-Meier survival analysis and Cox Proportional Hazards regression model we estimated the time to development of retinopathy in the two groups.

Results: Prevalence of retinopathy was $27.9 \%$ in THD group, as compared to $55.1 \%$ in the DM2 group ( $\mathrm{p}<0.001)$. THD were less than onethird as likely to have concurrent retinopathy than, DM2 patients (OR=0.32; $95 \% \mathrm{CI}=0.21$ to $0.48 ; \mathrm{p}<0.001)$. There was a significant difference in the median time to retinopathy between THD and DM2 patients (21.0yrs vs. 13.0yrs: Log-Rank p $<0.001)$. Risk of developing retinopathy in THD patients was two-fifths of that of DM2 patients (hazard ratio=0.418; $\mathrm{p}<0.001$ ) in a time-dependent variable analysis. The risk of developing retinopathy was concomitantly lower for patients with longer duration of hypothyroidism and thyroxine treatment prior to diagnosis of diabetes (Hazard ratio=0.957:p=0.004).

Conclusion: A significant sparing effect on development of retinopathy was noted in type 2 diabetic patients with concomitant hypothyroidism (on thyroxine). The exact mechanism(s) for these observations remain to be elucidated.

Keywords: Type 2 diabetes; Hypothyroidism; Diabetic retinopathy; Thyroxine

\section{Introduction}

Diabetes related complications are a major health burden worldwide. Tight control of blood glucose and blood pressure delays the onset of complications and reduces rate of progression, including diabetic retinopathy $[1,2]$. Potential risk factors implicated in the onset of retinopathy include metabolic, haemodynamic and possibly hormonal aberration [3,4]. Low levels of plasma thyroid hormone has been associated with macrovascular complication [5-7]. Furthermore it has been shown that hypothyroidism is a risk factor for atherosclerosis, and thyroid hormone replacement has beneficial effects on the atherogenic process $[8,9]$.

Patients with diabetes have a higher incidence of thyroid dysfunction, compared to that reported in the general population (10-13\%) [10-12]. Indeed there exists a state of hypothyroidism in patients with diabetes and in time both hypothyroidism and diabetes can lead to harmful metabolic derangement $[12,13]$.
The impact of thyroid status in the development of diabetic microvascular complications is unknown. There is scant information in literature on the impact of thyroid status on diabetes microvascular complications $[14,15]$. Based on our findings from a pilot study, [16] we therefore decided to conduct a retrospective case control study to ascertain the prevalence of retinopathy in thyroxine treated patients with diabetes.

\section{Methods}

\section{Study design}

A retrospective cohort study with data collected from case records and a clinical database was undertaken. Study subjects were selected from patients attending diabetes clinics at a single centre during the 2001 calendar year. Patients attending these diabetes clinics have regular clinical evaluation, blood pressure measurements, biochemical profiles and are monitored annually 
for thyroid function and detailed eye examination included retinal photography. In a recent audit of this centre, a $100 \%$ annual eye examination and diabetes care profile was noted [17].

Patients with diabetes and primary hypothyroidism, on oral thyroxine replacement, and duration of diabetes-matched controls without biochemical evidence of hypothyroidism were selected for the study. Information with regards to retinopathy was collected from ophthalmology notes and retinal photographs. Date of diagnosis of diabetes and first entry of retinopathy were abstracted from patient records and if necessary collected from patients or from their primary care physicians, when possible, for both the groups.

We identified 152 subjects with coexisting Type 2 diabetes and hypothyroidism on thyroxine therapy. Five of these subjects were excluded from further analyses as there was no information available on their retinopathy status. From an initial attempt to match at least 3 non-hypothyroid patients per hypothyroid patient with respect to the duration of diabetes, 417 patients who had Type 2 diabetes and a thyroid function test result confirming that they were biochemically euthyroid were selected. Subsequently, non-hypothyroid patients for whom no retinopathy data $(n=26)$ existed and who had recently received treatment for thyrotoxicosis $(n=8)$ were excluded from further analyses. Patients were not matched on the basis of gender as an anticipated preponderance of women among hypothyroid patients was to be subsequently controlled for analysis. Data with regards to their thyroid function test, Hba1c, blood pressure, creatinine, body weight and medication were abstracted from their records for all patients.

\section{Statistical analysis}

Standard statistical methods including chi-square and Kaplan-Meier survival analyses were employed to contrast the prevalence of retinopathy, and time to development of retinopathy from diabetes diagnosis, respectively, between thyroxine-treated hypothyroid diabetics and non-hypothyroid diabetics. Tests of equality of strata in Kaplan-Meier estimates were performed using both the Log-rank test and the Wilcoxon test. For both prevalence and Kaplan-Meier estimates, separate analyses were conducted in which hypothyroid diabetic patients who developed retinopathy prior to developing hypothyroidism were analysed as either hypothyroid (i.e. ignoring the temporal relationship between hypothyroidism and retinopathy), nonhypothyroid (acknowledging the temporal relationship) or in a separate category. In order to more explicitly account for the actual "period at risk" of hypothyroidism, univariate and multiple variable Cox Proportional Hazards Regression models were developed in which hypothyroidism was treated as a timedependent variable in the analysis of time to development of diabetic retinopathy from diagnosis of diabetes mellitus. In addition to controlling for possible age and gender influences, the potential for any concomitant effect of duration of hypothyroidism prior to the development of diabetes on the subsequent risk of development of retinopathy was assessed through the inclusion of an additional parameter in the model accounting for the period of hypothyroidism prior to diabetes diagnosis. In all survival analyses the temporal unit of analysis was calendar year. All statistical analyses were conducted using SAS version 8.02 software (SAS Institute Inc, Cary NC, USA) and statistical significance was considered achieved for $\mathrm{p}<0.05$.

\section{Results}

\section{Baseline characteristics}

Demographic details on the 147 hypothyroid and 383 nonhypothyroid type 2 diabetic patients available for analysis are presented in Table 1. Hypothyroidism was attributed to thyroidectomy (12), radio-iodine treatment (9), lithium treatment (1) or as either central (1), idiopathic (123) or unknown (1) aetiology. The mean $( \pm S D)$ age of the hypothyroid group was 66.2 years $( \pm 11.2)$ and that of the non-hypothyroid group was 62.6 years $( \pm 10.2)(p<0.001)$. No differences between the hypothyroid and non-hypothyroid groups in either the duration of diabetes (12.8 years vs. 13.0 years respectively; $\mathrm{p}=0.83$ ) or HbA1c (8.1gm\% vs. 8.0gm\% respectively; $\mathrm{p}=0.63$ ) were noted, however, as anticipated men comprised a significantly lower proportion of the hypothyroid group (19.1\% vs $54.8 \%$; $<<0.001)$. Systolic BP, along with TSH and FT4, were significantly higher in the hypothyroid group (Table 1).

Table 1: Demographics of patients with type2 diabetes and hypothyroidism on thyroxine replacement (THD) compared with patients with type2 diabetes without hypothyroidism (DM2). Cohort means for Hba1c, blood pressure, thyroid function profile and lipid profiles were calculated from the mean values for each patient, as determined from all available annual observations made over the 5-year period (1996-2001) prior to their selection.

\begin{tabular}{|c|c|c|c|c|c|}
\hline Covariate & Cohort & $\mathbf{N}$ & Mean & SD & $\mathbf{P}$ \\
\hline \multirow{2}{*}{ Age (years) } & THD & 147 & 66.2 & 10.28 & \multirow{2}{*}{0.001} \\
\hline & DM2 & 383 & 62.67 & 11.2 & \\
\hline \multirow{2}{*}{ Duration of diabetes (years) } & THD & 147 & 12.89 & 7.83 & \multirow{2}{*}{0.83} \\
\hline & DM2 & 382 & 13.04 & 7.35 & \\
\hline \multirow{2}{*}{ Systolic BP (mmHg) } & THD & 147 & 147.68 & 18.12 & \multirow{2}{*}{0.03} \\
\hline & DM2 & 383 & 144.23 & 15.98 & \\
\hline
\end{tabular}


Journal of Endocrinology and Thyroid Research

\begin{tabular}{|c|c|c|c|c|c|}
\hline \multirow{2}{*}{ Diastolic BP (mmHg) } & THD & 147 & 79.97 & 8.21 & \multirow{2}{*}{0.8} \\
\hline & DM2 & 383 & 80.17 & 8.71 & \\
\hline \multirow{2}{*}{ Cholesterol $(\mathrm{mmol} / \mathrm{l})$} & THD & 143 & 5.49 & 1.12 & \multirow{2}{*}{0.31} \\
\hline & DM2 & 383 & 5.38 & 1.11 & \\
\hline \multirow{2}{*}{ Triglyceride (mmol/l) } & THD & 130 & 2.16 & 1.38 & \multirow{2}{*}{0.13} \\
\hline & DM2 & 380 & 2.59 & 3.19 & \\
\hline \multirow{2}{*}{ HDL Cholesterol (mmol/l) } & THD & 114 & 1.35 & 0.39 & \multirow{2}{*}{0.42} \\
\hline & DM2 & 357 & 1.27 & 1.12 & \\
\hline \multirow{2}{*}{ LDL Cholesterol (mmol/l) } & THD & 43 & 2.9 & 0.92 & \multirow{2}{*}{0.9} \\
\hline & DM2 & 303 & 2.9 & 0.85 & \\
\hline \multirow{2}{*}{$\begin{array}{l}\text { Thyroid Stimulating Hormone (TSH in } \\
\mathrm{mU} / \mathrm{l} \text { ) }\end{array}$} & THD & 147 & 4.29 & 4.34 & \multirow[t]{2}{*}{$<0.001$} \\
\hline & DM2 & 383 & 1.91 & 0.99 & \\
\hline \multirow{2}{*}{ Free triiodothyronine (FT3 in pmol/l) } & THD & 60 & 3.35 & 1.37 & \multirow{2}{*}{0.1} \\
\hline & DM2 & 22 & 3.89 & 1.21 & \\
\hline \multirow{2}{*}{ FreeThyroxine (FT4 in nmol/l) } & THD & 136 & 16.81 & 3.87 & \multirow{2}{*}{$<0.001$} \\
\hline & DM2 & 146 & 15.17 & 2.56 & \\
\hline \multirow{2}{*}{ HbA1c (gm \%) } & THD & 147 & 8.12 & 1.22 & \multirow{2}{*}{0.63} \\
\hline & DM2 & 382 & 8.02 & 2.29 & \\
\hline \multirow{2}{*}{ Weight (kg) } & THD & 142 & 82.37 & 18.4 & \multirow{2}{*}{0.007} \\
\hline & DM2 & 378 & 87.02 & 17 & \\
\hline \multirow{2}{*}{ Creatinine (nmol/l) } & THD & 146 & 103.43 & 41.6 & \multirow{2}{*}{0.63} \\
\hline & DM2 & 380 & 101.25 & 49 & \\
\hline \multirow{2}{*}{ Males } & THD & \multirow{2}{*}{\multicolumn{3}{|c|}{$\begin{array}{l}28 / 147=19.1 \% \\
210 / 383=54.8 \%\end{array}$}} & \\
\hline & DM2 & & & & $<0.001$ \\
\hline
\end{tabular}

\section{Prevalence and severity of retinopathy}

The prevalence of any degree of retinopathy was $55.1 \%$ in the non-hypothyroid group, compared to only $27.9 \%$ in the hypothyroid group (Table 2 (I)A; $\mathrm{p}<0.001$ ) such that the patients who ever experienced hypothyroidism were less than onethird as likely to suffer from concurrent retinopathy than those patients who had type 2 diabetes but were never hypothyroid. (Odds Ratio $=0.32 ; 95 \% \mathrm{CI}=0.21-0.48 ; \mathrm{p}<0.001$ ). There was no significant difference by gender when this was simultaneously controlled for $(\mathrm{p}=0.63)$. However, of the 41 hypothyroid patients who had evidence of retinopathy 14 were diagnosed with hypothyroidism after developing retinopathy, with an average time between diagnoses of 4.7 years (median $=3.0, \mathrm{SD}=4.0, \mathrm{~min}=1$, $\max =15$ ). When the data was analysed with these 14 patients reclassified as 'non-hypothyroid' (i.e. at the time of development of retinopathy), a stronger sparing effect of hypothyroidism on the development of diabetic retinopathy was observed (Table 2- IB); Odds Ratio=0.19; 95\% CI=0.12-0.31; $\mathrm{p}<0.001$ ), although once again, no difference by gender was noted when this was simultaneously controlled for ( $\mathrm{p}=0.87)$.

Of the 252 patients with retinopathy, the prevalence of more severe (classified as sight-threatening) retinopathy was greater in the non-hypothyroid group $(121 / 211=57.4 \%)$ than in the hypothyroid group $(15 / 41=36.6 \%$; $<<0.001$, Table 2 - IIA), with no gender differences $(\mathrm{p}=0.32)$. That is to say, type 2 diabetic patients with retinopathy who ever experienced hypothyroidism were less than one-half as likely to suffer from severe, sightthreatening retinopathy than those patients who had type 2 diabetes and retinopathy but were never hypothyroid $(\mathrm{OR}=0.43$; $95 \% \mathrm{CI}=0.21-0.86)$. When the 14 patients whose diagnosis of retinopathy preceded the diagnosis of hypothyroidism were once again reclassified, the sparing effect of hypothyroidism once again became stronger $(\mathrm{OR}=0.16 ; 95 \% \mathrm{CI}=0.06-0.44$; Table 2 - IIB), while the influence of gender remained non-significant $(\mathrm{p}=0.55)$.

\section{Time to development of retinopathy}

Two non-hypothyroid patients and one hypothyroid patient did not have dates of onset of diabetes recorded and were therefore excluded from all time to event analyses. The results of Kaplan-Meier analysis of time to retinopathy between the two groups, in which hypothyroid status was treated as a timeinvariant covariate, are presented in Table 2 (III)A through $\mathrm{C}$ and in corresponding Figure 1 (Panel A-C). 


\section{Journal of Endocrinology and Thyroid Research}

Table 2: (I) Comparison of proportion of patients with any degree of retinopathy by hypothyroid status without (A) and with (B) reclassification of the 14 patients whose diagnosis of diabetic retinopathy preceded the diagnosis of hypothyroidism. (II) Comparison of proportion of sight threatening retinopathy (STR) among patients with any degree of retinopathy by hypothyroid status without (A) and with (B) reclassification of the 14 patients whose diagnosis of diabetic retinopathy preceded the diagnosis of hypothyroidism; (III) Time from diagnosis with diabetes to development of any degree of retinopathy in years by hypothyroid status without (A), with (B) and with separate $(C)$ reclassification of the 14 patients whose diagnosis of diabetic retinopathy preceded the diagnosis of hypothyroidism.

\begin{tabular}{|c|c|c|c|c|c|}
\hline (I) & & Hypothyroid & Non-Hypothyroid & Odds Ratio & 95\% CI \\
\hline \multirow{4}{*}{ Retinopathy } & \multirow[b]{2}{*}{ A } & At any time & & \multirow{2}{*}{$\begin{array}{c}0.32 \\
(0.33)^{*}\end{array}$} & \multirow{2}{*}{$\begin{array}{c}0.21-0.48 \\
(0.21-0.50)^{*}\end{array}$} \\
\hline & & $\begin{array}{l}41 / 147 \\
(27.9 \%)\end{array}$ & $\begin{array}{c}211 / 383 \\
(55.1 \%)\end{array}$ & & \\
\hline & \multirow[b]{2}{*}{ B } & Before Retinopathy & or Hypothyroid after Retinopathy & \multirow{2}{*}{$\begin{array}{c}0.19 \\
(0.19)^{* *}\end{array}$} & \multirow{2}{*}{$\begin{array}{c}0.12-0.31 \\
(0.12-0.31)^{* *}\end{array}$} \\
\hline & & $\begin{array}{l}27 / 133 \\
(20.3 \%)\end{array}$ & $\begin{array}{c}225 / 397 \\
(56.7 \%)\end{array}$ & & \\
\hline \multicolumn{6}{|c|}{${ }^{*} \mathrm{OR}$ and $95 \% \mathrm{CI}$ while simultaneously controlling for effect of gender $(\mathrm{p}=0.63)$} \\
\hline \multicolumn{6}{|c|}{ **OR and $95 \%$ CI while simultaneously controlling for effect of gender $(\mathrm{p}=0.87)$} \\
\hline
\end{tabular}

(I)

\begin{tabular}{|c|c|c|c|c|c|}
\hline & & Hypothyroid & Non-Hypothyroid & Odds Ratio & $95 \%$ CI \\
\hline \multirow{4}{*}{ STR } & \multirow{2}{*}{ A } & At any time & & \multirow{2}{*}{$0.43(0.46)^{*}$} & \multirow{2}{*}{$\begin{array}{c}0.21-0.86 \\
(0.23-0.94)^{*}\end{array}$} \\
\hline & & $15 / 41-36.6 \%$ & $121 / 211-57.4 \%$ & & \\
\hline & \multirow[b]{2}{*}{ B } & Before Retinopathy & or Hypothyroid after Retinopathy & \multirow[b]{2}{*}{$0.16(0.17)^{* *}$} & \multirow[b]{2}{*}{$\begin{array}{c}0.06-0.44 \\
(0.06-0.48)^{* *}\end{array}$} \\
\hline & & $\begin{array}{l}5 / 27 / 2018 \\
-18.5 \%\end{array}$ & $\begin{array}{c}131 / 225 \\
-58.2 \%\end{array}$ & & \\
\hline \multicolumn{6}{|c|}{$* \mathrm{OR}$ and $95 \% \mathrm{CI}$ while simultaneously controlling for effect of gender $(\mathrm{p}=0.63)$} \\
\hline \multicolumn{6}{|c|}{${ }^{* *}$ OR and $95 \%$ CI while simultaneously controlling for effect of gender $(\mathrm{p}=0.87)$} \\
\hline
\end{tabular}

(II)

\begin{tabular}{|c|c|c|c|c|c|c|c|}
\hline & \multirow{2}{*}{ Hypothyroid Status and Timing } & \multirow{2}{*}{ Total } & \multirow{2}{*}{ Retinopathy } & \multirow{2}{*}{$\begin{array}{c}\% \\
\text { censored }\end{array}$} & \multicolumn{3}{|c|}{ Time to Retinopathy from Diabetes (years) } \\
\hline & & & & & Median & Mean & p \\
\hline \multirow[b]{2}{*}{ A } & Non-Hypothyroid & 381 & 210 & 44.9 & 13 & 14.8 & \multirow{2}{*}{$<0.001$} \\
\hline & Hypothyroid at any time & 146 & 40 & 72.6 & 21 & 18 & \\
\hline \multirow{2}{*}{ B } & $\begin{array}{l}\text { Non-Hypothyroid or Hypothyroid after } \\
\text { Retinopathy }\end{array}$ & 395 & 224 & 43.3 & 13 & 14.3 & \multirow{2}{*}{$<0.001$} \\
\hline & Hypothyroid before Retinopathy & 132 & 26 & 80.3 & 20 & 16.7 & \\
\hline \multirow{3}{*}{$\mathrm{C}$} & Non-Hypothyroid & 381 & 210 & 44.9 & 13 & 14.8 & \multirow{3}{*}{$<0.001$} \\
\hline & Hypothyroid after Retinopathy & 14 & 14 & 0 & 11 & 11.6 & \\
\hline & Hypothyroid before Retinopathy & 132 & 26 & 80.3 & 20 & 16.7 & \\
\hline
\end{tabular}

(III)

When all hypothyroid diabetics, regardless of when they developed hypothyroidism (before or after retinopathy) were compared to the non-hypothyroid controls, the time to development of retinopathy was significantly shorter in the patients who had never experienced hypothyroidism (Table 2- IIIA) - median $=13$ vs. 21 years; $\mathrm{p}<0.001$; Figure 1 Panel A) with a hazard ratio (HR) of 0.425 (Table $3 \mathrm{~A}$ ), with no significant differences by gender $(p=0.24)$. However, when the
14 patients who developed hypothyroidism after retinopathy were analysed separately (Table 2 IIC and Figure 1 Panel B) the time to development of retinopathy in this subgroup differed significantly from the other hypothyroid patients $(\mathrm{p}<0.001)$, but not from the non-hypothyroid group $(\mathrm{p}=0.23)$, and again with no overall differences noted between the genders $(p=0.39)$. These results supported the inclusion of these 14 patients within the non-hypothyroid group in an overall contrast of patients who had 
never experienced hypothyroidism or whose hypothyroidism occurred after the development of retinopathy vs. those patients whose hypothyroidism preceded the development of retinopathy (Table 2 IIIB and Figure-1 Panel C). Unsurprisingly the result was an increase in the distinction in time to development of retinopathy between these two categories (HR=0.302; Table 3B), but again with no effect of gender $(\mathrm{p}=0.40)$. Risk of development of sight threatening retinopathy (STR) could not be similarly analysed owing to lack of information on dates of progression of severity of retinopathy.

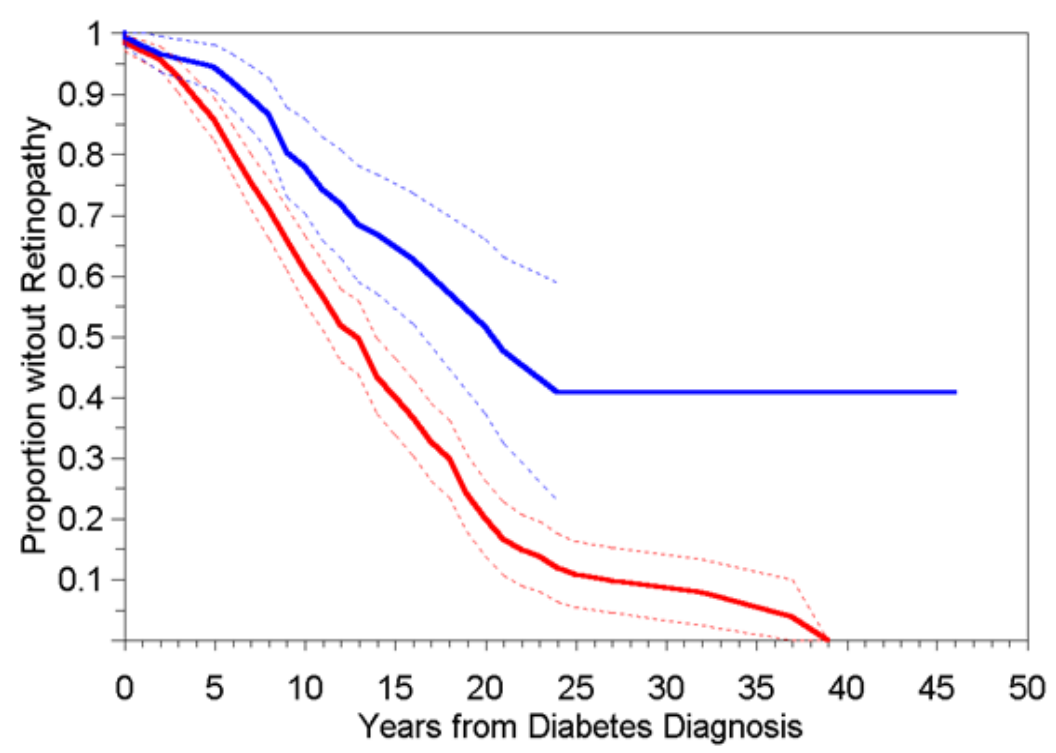

Figure 1 (panel A): Event free survival (development of retinopathy) in 146 patients with type 2 diabetes and hypothyroidism (一; $95 \% \mathrm{Cl}$ ---) compared to 381 patients with type 2 diabetes but no hypothyroidism (-); $95 \% \mathrm{Cl}---)$, where no significant differences by gender were observed $(p=0.24)$.

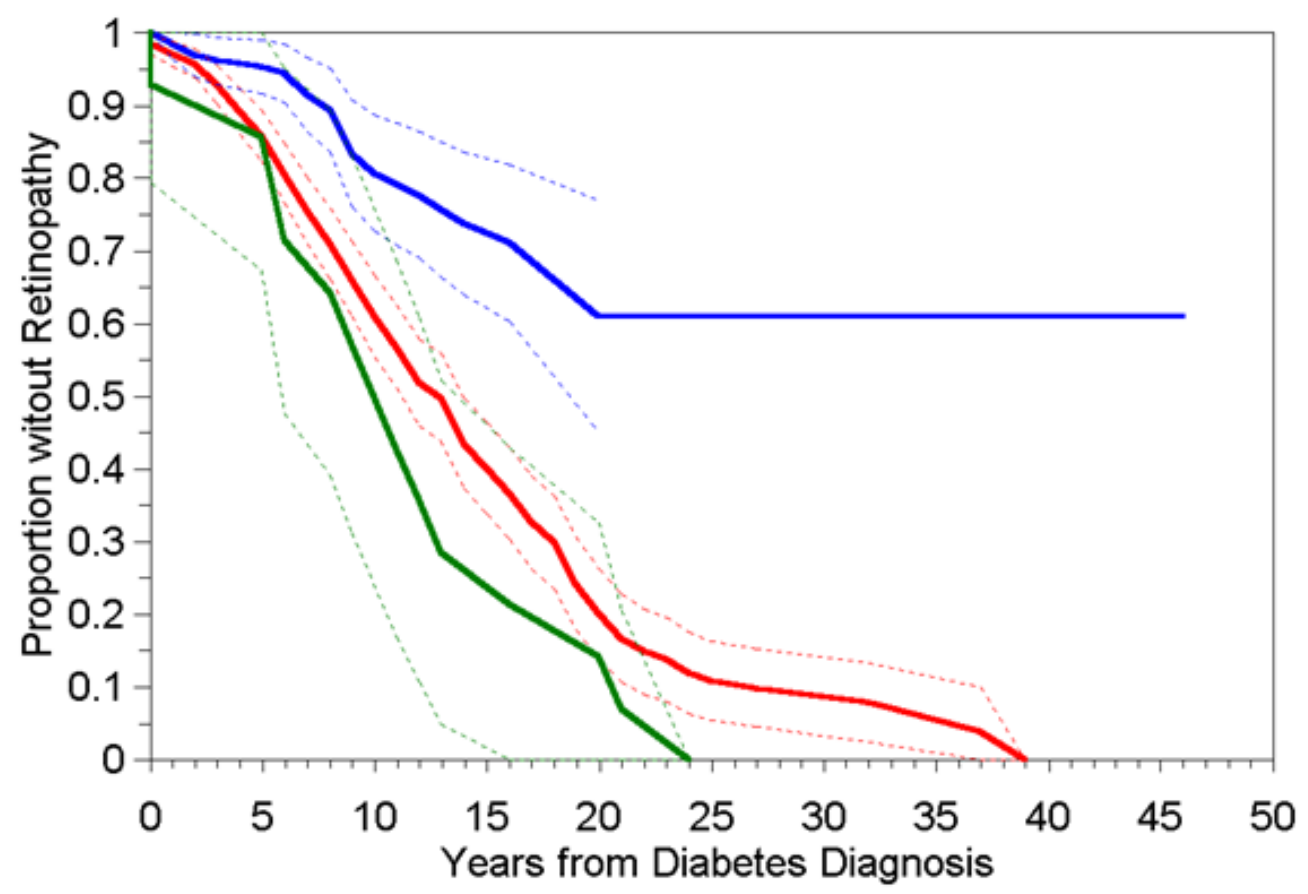

Figure 1 (Panel B): Event free survival (development of retinopathy) in 132 patients with type 2 diabetes and hypothyroidism, where the diagnosis of hypothyroidism preceded the development of retinopathy $(-; 95 \% \mathrm{Cl}---)$ compared to 381 patients with type 2 diabetes but no hypothyroidism (-); $95 \% \mathrm{Cl}$---) and 14 patients with type 2 diabetes and hypothyroidism, where the development of retinopathy preceded the diagnosis of hypothyroidism $(-; 95 \% \mathrm{Cl}---)$, where no significant differences by gender were observed $(p=0.40)$. 


\section{Journal of Endocrinology and Thyroid Research}

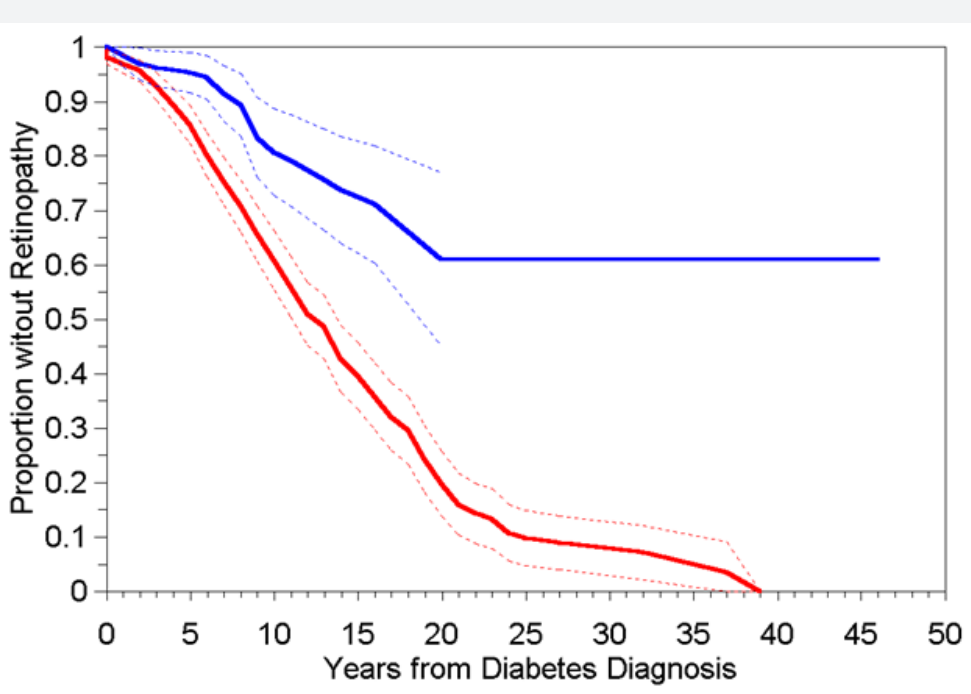

Figure 1 (Panel C): Event free survival (development of retinopathy) in 132 patients with type 2 diabetes and hypothyroidism, where the diagnosis of hypothyroidism preceded the development of retinopathy (-;95\% Cl ---) compared to 395 patients with type 2 diabetes but no hypothyroidism or where the development of retinopathy preceded the diagnosis of hypothyroidism (-; $95 \% \mathrm{Cl}---)$, where no significant differences by gender were observed $(p=0.39)$.

Table 3: Results of Cox Proportional Hazards Regressions of time from diagnosis with type 2 diabetes to development of any degree of retinopathy in years.

\begin{tabular}{|c|c|c|c|}
\hline & Covariates in Model & Hazard Ratio & $\mathbf{P}$ \\
\hline A & Hypothyroid at any time - time-invariant & 0.425 & $<0.001$ \\
\hline B & $\begin{array}{l}\text { Hypothyroid prior to development of retinopathy - } \\
\text { time-invariant }\end{array}$ & 0.302 & $<0.001$ \\
\hline $\mathrm{C}$ & Hypothyroid - as time-dependent variable & 0.418 & $<0.001$ \\
\hline \multirow{4}{*}{ D } & Age at diabetes diagnosis & 1.022 & $<0.001$ \\
\hline & Gender (Male) & 1.246 & 0.1 \\
\hline & Ethnic Group (Caucasian) & 0.82 & 0.28 \\
\hline & Hypothyroid - as time-dependent variable & 0.395 & $<0.001$ \\
\hline \multirow{5}{*}{ E } & Age at diabetes diagnosis & 1.019 & 0.003 \\
\hline & Gender (Male) & 1.22 & 0.14 \\
\hline & Ethnic Group (Caucasian) & 0.845 & 0.36 \\
\hline & Hypothyroid - as time-dependent variable & 0.464 & $<0.001$ \\
\hline & $\begin{array}{c}\text { Years hypothyroid diagnosis preceded diabetes } \\
\text { diagnosis }\end{array}$ & 0.957 & 0.004 \\
\hline \multirow{6}{*}{$\mathrm{F}$} & Age at diabetes diagnosis & 1.021 & 0.002 \\
\hline & Gender (Male) & 1.222 & 0.13 \\
\hline & Ethnic Group (Caucasian) & 0.798 & 0.24 \\
\hline & Hypothyroid - as time-dependent variable & 0.49 & 0.003 \\
\hline & $\begin{array}{c}\text { Years hypothyroid diagnosis preceded diabetes } \\
\text { diagnosis }\end{array}$ & 0.956 & 0.004 \\
\hline & $\begin{array}{c}\text { Receiving insulin - at final } 2002 \text { observation, time- } \\
\text { invariant }\end{array}$ & 1.167 & 0.3 \\
\hline \multirow{3}{*}{ G } & Age at diabetes diagnosis & 1.018 & 0.027 \\
\hline & Gender (Male) & 1.25 & 0.18 \\
\hline & Ethnic Group (Caucasian) & 0.873 & 0.55 \\
\hline
\end{tabular}


Journal of Endocrinology and Thyroid Research

\begin{tabular}{|c|c|c|c|}
\hline \multirow{2}{*}{} & Hypothyroid - as time-dependent variable & 0.458 & 0.002 \\
\cline { 2 - 4 } & $\begin{array}{c}\text { Years hypothyroid diagnosis preceded diabetes } \\
\text { diagnosis }\end{array}$ & 0.96 & 0.011 \\
\cline { 2 - 4 } & Receiving insulin - as time-dependent variable* & 1.747 & 0.002 \\
\hline
\end{tabular}

*Information on the commencement of insulin therapy was available for only 147 of the 307 patients reported to be receiving insulin in 2002 such that 160 patients receiving insulin, but without date of initiation are censored at time $=0$.

\section{Hypothyroidism as time-dependent variable}

In Cox Proportional Hazard Regression models in which hypothyroidism was treated as a time-dependent variable in assessing the risk of developing diabetic retinopathy (Table 3C) an unadjusted hazard ratio of $0.418(\mathrm{p}<0.001)$ was observed, again denoting a significantly reduced risk of developing retinopathy for those patients who suffer from hypothyroidism. Further adjusting for the effects of age at diabetes diagnosis, gender and ethnic group marginally reduced the hazard ratio further to 0.395 ( $p<0.001$; Table 3D). Of the 147 patients with hypothyroidism and diabetes 102 patients had hypothyroidism diagnosed at least 1 year prior to, 38 after and 7 at the same time of diagnosis of diabetes. Thus, in a model also incorporating a covariate corresponding to the years of hypothyroidism experienced by a patient prior to their diagnosis of diabetes, not only did hypothyroidism maintain its apparently protective effect (HR=0.464; $\mathrm{p}<0.001)$, but there was an additional reduction in risk of developing retinopathy in 102 hypothyroid patients for each year their hypothyroidism preceded their diabetes (HR=0.957; $p=0.004$; Table 3E).

\section{Discussion}

In the present study we demonstrate for the first time that patients with type 2 diabetes and coexisting hypothyroidism (on thyroxine replacement) have a decreased risk of developing diabetic retinopathy. In thyroxine-treated hypothyroid patients with diabetes (THD) and controls, beside thyroid function, recent biochemical profiles did not differ appreciably between the two groups (Table 1). The sparing effect of retinopathy in THD was significant despite patients being older and having higher systolic blood pressure than controls. The mean TSH and free thyroxine values were significantly higher in the THD group as compared to controls; the higher TSH value in the context of high free thyroxine value in THD group may be explained by certain non-compliant individuals, as seen in clinical practice. Importantly, patients who developed hypothyroidism after retinopathy were no different from controls, however we could not analyse the effect of progression of this group to sight threatening retinopathy (STR) because of insufficient information with regards to time of onset of STR.

Effect of thyroid extracts on diabetic retinopathy has been previously studied in 19 insulin dependent diabetics over a period of 2 years by Schneider et al. Twelve of the 19 cases showed improvement while on thyroid extract with reduction in haemorrhages and exudates, and this improvement was maintained whilst the patients were on thyroid extract [18].
Although there have been a few case reports highlighting the absence of complications in patients with coexisting diabetes and hypothyroidism who were on thyroxine replacement, these have not been confirmed in a larger population [14].

Our data shows a larger sparing effect, proportional to the interval of diagnosis, was observed in patients who developed hypothyroidism before the diagnosis of diabetes mellitus, and persisted after controlling for age and gender. The possibility that being diagnosed to have hypothyroidism may have resulted in an increased surveillance for diabetes in these patients, and therefore be a plausible explanation of our observations, is unlikely as it is not standard practice to screen hypothyroid patients for Type 2 diabetes. Potential explanations include that the two groups may be genetically different and hence have a different predisposition rate to retinopathy, or possibly the thyroxine replacement in THD subjects had in some way altered their hypothalamic-pituitary axis, which contributed to the sparing effect from development of retinopathy.

In patients with diabetes there exists a dysfunctional state of thyroid homeostasis, $[12,19]$ which is dependent on the degree of metabolic control [20,21]. Improving diabetes control per se does not seem to influence free thyroid hormone level or its effect on the pituitary axis which could possibly explain why certain patients develop retinopathy in spite of good control and vice versa [22]. It is evident from animal and human studies plasma free T3 and free T4 are decreased and rT3 is increased, in addition there also exists a defect in hypothalamic regulation of the thyroid -pituitary feedback system suggesting a state sick euthyroid in patients with diabetes $[23,24]$. In diabetes the conversion of FT4 to FT3 is also decreased in several tissues and regulation of TSH secretion is altered in poorly controlled diabetes $[25,26]$. The dysfunctional state of thyroid homeostasis may have contributed to the higher prevalence of retinopathy in the non-hypothyroid group by virtue of not being on thyroxine supplement.

Studies have shown regression of retinopathy after complete ablation of the pituitary gland [27]. The regression of retinopathy is believed to be as a result of loss of anterior pituitary hormones, including growth hormone. Interaction of other hormones including thyroid hormone (deficiency or adequate replacement) has not been clearly elucidated. Grant et al. [28], have shown a beneficial effect in diabetic patients with severe non-proliferative retinopathy treated with high dose octreotide, although following octreotide treatment patients required thyroxine replacement to maintain a euthyroid state [28]. Given 
the recent evidence of thyroid homeostatsis and macrovascular disease the role of pituitary-thyroid axis in the aetiopathogenesis of diabetic microvascular disease is interesting.

This altered state of thyroid homeostasis in diabetes may play a role in the increased atherosclerotic process, a major risk factor for both micro- and macro-vascular complication $[12,19]$. Studies in diabetic rats with retinal microangiopathy, as evidenced by capillary basement membrane thickening, plasma thyroxine was found to be reduced after 8 months, and triiodothyronine at 8 and 12 months as compared to controls [29]. In addition, thyroxine deficiency in diabetic rats results in altered vascular reactivity which is reversible on thyroxine supplement [30].

The limitations of our present observational study include data over time with regards to all the covariates could not be analysed in a time varying analysis. In addition progression of retinopathy to STR in patients with concurrent hypothyroidism could not be analysed. Questions with regards to dosage of thyroxine and other possible aetiopathogenic factors including the dynamics of hypothalamic pituitary axis over time were not recorded with sufficient intensity to be analysed in the current study and would undoubtedly require a large prospective study. These studies could possibly increase the understanding with regards to pathogenesis of diabetic retinopathy and possible therapeutic implications in future warranting further research.

In conclusion, our present study shows that concurrent hypothyroidism, treated with thyroxine, appears to have a sparing effect on the risk of developing retinopathy among patients with type 2 diabetes. The exact mechanism(s) of this sparing effect are unclear. Further prospective studies are warranted in order to elucidate the precise nature of this phenomenon.

\section{Acknowledgement}

This study was supported in part by a grant from the Diabetes and Medical Research Fund.

\section{References}

1. Stratton IM, Kohner EM, Aldington SJ, Turner RC, Holman RR, et al. (2001) UKPDS 50: risk factors for incidence and progression of retinopathy in Type II diabetes over 6 years from diagnosis Diabetologia 44(2): 156-163.

2. (1995) The relationship of glycemic exposure (HbA1c) to the risk of development and progression of retinopathy in the diabetes control and complications trial. Diabetes 44(8): 968-983.

3. Poulsen JE (1967) Diabetes mellitus. Lectures held in Cairo and Alexandria, January 1966. Acta Endocrinol (Copenh): Suppl 118: 5-95.

4. Poulsen JE (1966) Diabetes and anterior pituitary insufficiency. Final course and postmortem study of a diabetic patient with Sheehan's syndrome. Diabetes 15(2): 73-77.

5. Gray RS, Smith AF, Clarke BF (1981) Hypercholesterolemia in diabetics with clinically unrecognised primary thyroid failure. Horm Metab Res 13(9): 508-510.

6. Bruckert E, Giral P, Chadarevian R, Turpin G (1999) Low free-thyroxine levels are a risk factor for subclinical atherosclerosis in euthyroid hyperlipidemic patients. J Cardiovasc Risk 6(5): 327-331.
7. Miura S, Iitaka M, Suzuki S, Fukasawa N, Kitahama S, et al. (1996) Decrease in serum levels of thyroid hormone in patients with coronary heart disease. Endocr J 43(6): 657-663.

8. Perk M, O Neill BJ (1997) The effect of thyroid hormone therapy on angiographic coronary artery disease progression. Can J Cardiol 13(3): 273-276.

9. Staub JJ, Althaus BU, Engler H, Ryff AS, Trabucco P, et al. (1992) Spectrum of subclinical and overt hypothyroidism: effect on thyrotropin, prolactin, and thyroid reserve, and metabolic impact on peripheral target tissues. Am J Med 92(6): 631-642.

10. Perros P, McCrimmon RJ, Shaw G, Frier BM (1995) Frequency of thyroid dysfunction in diabetic patients: value of annual screening. Diabet Med 12(7): 622-627.

11. Gray RS, Borsey DQ, Seth J, Herd R, Brown NS, et al. (1980) Prevalence of subclinical thyroid failure in insulin-dependent diabetes. J Clin Endocrinol Metab 50(6):1034-1037.

12. Bagchi N (1982) Thyroid function in a diabetic population. Spec Top Endocrinol Metab 3: 45-55.

13. Nakamura S, Sakata S, Kojima N, Komaki T, Matsuda M, et al. (1987) Serum thyroglobulin concentration in patients with diabetes mellitus. Endocrinol Jpn 34(4): 473-478.

14. Glick SM (1961) Diabetes mellitus and cretinism: report of a case free of complications after 27 years. Metabolism 10: 788-793.

15. Baron DN (1955) Hypothyroidism and diabetes mellitus. Lancet 269: 796-798.

16. Sailesh S, Philip S, Panja S, Randeva H, Hillhouse E, et al. (2000) Thyroxine supplement in patients with hypothyroidism is associated with a reduced prevalence of retinopathy in type 2 diabetes: EASD Jerusalem. Diabetologia 36: S713-S714.

17. Lee JD, Sailesh S, Patel V (2002) Alphabet POEM Audit project EASD Budapest. Diabetologia 11: S181-S186.

18. Schneider T, Meyerson L (1969) Thyroid therapy in diabetic retinopathy. S Afr Med J 43: 414-417.

19. Custro N, Scafidi V, Costanzo G, Casiglia D (1989) Thyroid hormone anomalies in patients with insulin-dependent diabetes mellitus and circulating antithyroid microsomal antibodies. Minerva Med 80(5): 427-430.

20. Kabadi UM, Premachandra BN, Maayan M (1982) Low serum 3, 5 3'-triiodothyronine (T3) and raised 3, 3', 5'-triidothyronine (reverse T3 or RT3) in diabetes mellitus: normalization on improvement in hyperglycemia. Acta Diabetol Lat 19(3): 233-242.

21. Dorchy H, Bourdoux P, Lemiere B (1985) Subclinical thyroid hormone abnormalities in type I diabetic children and adolescents. Relationship to metabolic control. Acta Paediatr Scand 74(3): 386-389.

22. Parr JH (1987) The effect of long-term metabolic control on free thyroid hormone levels in diabetics during insulin treatment. Ann Clin Biochem 24 (Pt 5): 466-469.

23. Bagchi N, Palaniswami N, Desai H, Felicetta J, Brown TR (1988) Decreased thyroidal response to thyrotropin in type II diabetes mellitus. Metabolism 37(7): 669-671.

24. Gilani BB, MacGillivray MH, Voorhess ML, Mills BJ, Riley WJ, et al. (1984) Thyroid hormone abnormalities at diagnosis of insulin-dependent diabetes mellitus in children. J Pediatr 105(2): 218-222.

25. Kabadi UM (1984) Impaired pituitary thyrotroph function in uncontrolled type II diabetes mellitus: normalization on recovery. J Clin Endocrinol Metab 59(3): 521-525.

26. Ortiz-Caro J, Obregon MJ, Pascual A, Jolin T (1984) Decreased T4 to T3 conversion in tissues of streptozotocin-diabetic rats. Acta Endocrinol (Copenh) 106(1): 86-91. 
27. Joplin GF, Oakley NW, Hill DW, Kohner EM, Fraser TR (1967) Diabetic retinopathy. II. Comparison of disease remission induced by various degrees of pituitary ablation by Y90. Diabetologia 3(4): 406-412.

28. Grant MB, Mames RN, Fitzgerald C, Hazariwala KM, Cooper-DeHoff $R$, et al. (2000) The efficacy of octreotide in the therapy of severe nonproliferative and early proliferative diabetic retinopathy: a randomized controlled study. Diabetes Care 23(4): 504-509.
29. Waber S, Meister V, Rossi GL, Mordasini RC, Riesen WF (1981) Studies on retinal microangiopathy and coronary macroangiopathy in rats with streptozotocin-induced diabetes. Virchows Arch B Cell Pathol Incl Mol Pathol 37(1): 1-10.

30. Takiguchi Y, Satoh N, Hashimoto H, Nakashima M (1989) Reversal effect of thyroxine on altered vascular reactivity in diabetic rats. J Cardiovasc Pharmacol 13(4): 520-524.

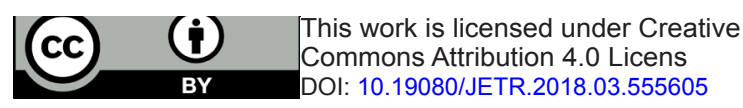

\begin{tabular}{l} 
Your next submission with Juniper Publishers \\
will reach you the below assets \\
- Quality Editorial service \\
- Swift Peer Review \\
- Reprints availability \\
- E-prints Service \\
- Manuscript Podcast for convenient understanding \\
- Global attainment for your research \\
- Manuscript accessibility in different formats \\
( Pdf, E-pub, Full Text, Audio) \\
- Unceasing customer service \\
Track the below URL for one-step submission \\
https://juniperpublishers.com/online-submission.php \\
\hline
\end{tabular}

